\title{
Recycling Waste Polyurethane as a Carbon Resource in Ironmaking*
}

\author{
${ }^{1}$ J. R. Dankwah and ${ }^{1}$ W. K. Buah \\ ${ }^{1}$ University of Mines and Technology, P.O. Box 237, Tarkwa, Ghana
}

Dankwah, J. R. and Buah, W.K. (2017), "Recycling Waste Polyurethane as Carbon Resource in Ironmaking", Ghana Mining Journal, Vol. 17, No. 1, pp. 73 - 77.

\begin{abstract}
Globally, major avenues available for dealing with waste Poly-Urethane (PU) are disposal at landfill sites and incineration. However, PU contains high levels of carbon and hydrogen that can be recovered for use as reductant in metal extraction processes. In this work the use of post-consumer PU as reductant for the production of metallic iron from iron oxide was investigated in a horizontal tube furnace through the composite pellet approach. Composite pellets were formed from mixtures of iron oxide and post-consumer PU. The iron oxide-PU composites were heated from room temperature to 1200 ${ }^{\circ} \mathrm{C}$ and then between $1200-1600{ }^{\circ} \mathrm{C}$ in a continuous stream of pure argon and the off gas was analysed continuously using an infrared (IR) gas analyser. Elemental analyses of samples of the reduced metal were performed chemically for its oxygen content using a LECO oxygen/nitrogen analyser. The extent of reduction was then determined at two temperatures $1200^{\circ} \mathrm{C}$ and $1550{ }^{\circ} \mathrm{C}$. Gas emission studies revealed the emission of large volumes of the reductant gas $\mathrm{CO}$ along with $\mathrm{CO}_{2}$. It is further demonstrated that post-consumer PU is effective at reducing iron oxide to produce metallic iron with complete reduction achieved in less than $4 \mathrm{~min}$ at $1550{ }^{\circ} \mathrm{C}$.
\end{abstract}

Keywords: Polyurethane, Composite Pellets, Infrared gas Analyser, LECO Carbon/Sulphur Analyser

\section{Introduction}

Globally, major avenues available for dealing with Poly-Urethane (PU) are disposal at landfill sites and incineration. However, PU contains high levels of carbon and hydrogen that can be recovered for use as reductant in metal extraction processes. In Ghana, recycling figures for waste PU are not available, although it is believed that significant amounts of PU are produced annually. Conventional methods for recycling PU have concentrated largely on disposal at landfill sites. Decreasing landfill space along with increasing landfill costs call for novel ways for its recycling.

Large amounts of waste PU are generated annually from various households, as part of medical waste from various hospitals and constitute a significant portion of automotive shredder waste.

PU (Fig. 1) contains appreciable levels of carbon and hydrogen and its thermal decomposition at high temperatures generates large amounts of the gaseous reducing species $\mathrm{CO}$ and $\mathrm{CH}_{4}$ along with solid $\mathrm{C}$ which are known reductants of metal oxides. It has no sulphur content, making it an ideal sulphur-free carbonaceous reductant for ironmaking. The use of waste polymeric materials as chemical feedstock in iron and steelmaking is currently gaining the attention of researchers [Matsuda et al., (2006), Matsuda et al., (2008), Murakami et al., (2009), Murakami and Kasai, (2011), Ueki et al., (2008), Dankwah et al., (2011), Nishioka et al., (2007), Dankwah et al., (2012), Dankwah et al., (2013), Dankwah and Koshy,
(2014), Dankwah and Baawuah, (2015) and Dankwah et al., (2015).].

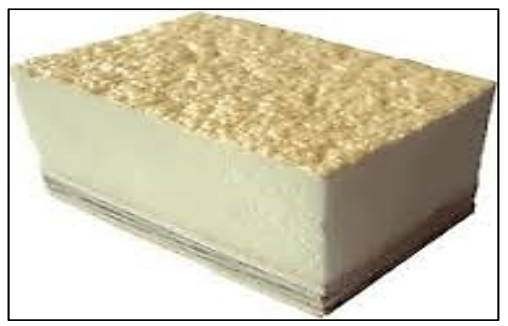

Fig. 1 Soft Polyurethane Foam

The interest in getting carbon from various sources has been extended to household items like bowls made from bakelite, melamine and compact discs (CDs) [Kongkarat et al., 2011; Mansuri et al., 2013; Nath et al., 2012; Rajarao et al., 2014a; Rajarao et al., 2014b].

However, not much is known about the use of PU as reductant in iron and steelmaking technologies. In the present work, the potential for producing metallic iron from hematite using waste PU as a reducing agent is investigated under inert atmosphere in a custom made horizontal tube furnace.

\section{Resources and Methods Used}

\subsection{Materials}

Commercial grade PU (pulverised to $125 \mu \mathrm{m}$ using a ring mill) was employed in this study as carbonaceous material. The chemical composition 
(wt \%) and the ash analyses as determined at the Analytical Centre, UNSW, Australia are given in Tables 1. Pulverised reagent grade iron oxide (assaying 96.89\% $\mathrm{Fe}_{2} \mathrm{O}_{3}$ ) was obtained from Ajax FineChem Pty Ltd, Taren Point, NSW, Australia; its composition (determined by XRF analysis) is given in Table 2.

Table 1 Elemental Analysis of Polyurethane

\begin{tabular}{lccccc}
\hline Component & C & H & O & N & S \\
\hline Composition wt \% & 65.6 & 4.9 & 20.5 & 9.0 & - \\
\hline
\end{tabular}

Table 2 Elemental Analysis of $\mathrm{Fe}_{2} \mathrm{O}_{3}$

\begin{tabular}{lc}
\hline Component & Composition (wt \%) \\
\hline $\mathrm{Fe}_{2} \mathrm{O}_{3}$ & 96.89 \\
$\mathrm{SiO}_{2}$ & 0.445 \\
$\mathrm{CaO}$ & 0.0225 \\
$\mathrm{MnO}$ & 0.020 \\
$\mathrm{ZnO}$ & 0.0115 \\
$\mathrm{TiO}_{2}$ & 0.134 \\
$\mathrm{SO}_{3}$ & 0.257 \\
$\mathrm{LOI}$ & 2.22 \\
TOTAL & 100 \\
\hline
\end{tabular}

Pulverised carbonaceous materials were prepared from PU using a Cutting Mill Pulverisette 15 (Fig. 2 ), equipped with a cutting rotor, sieve inserts and grinding chamber. Pulverised carbonaceous materials used for the reduction studies were in the size range $-470+450 \mu \mathrm{m}$.

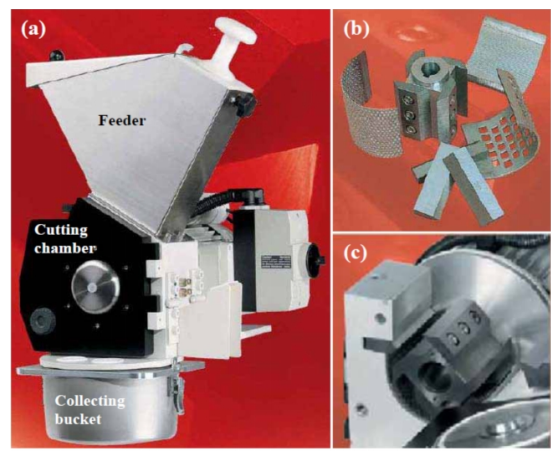

Fig. 2 (a) Cutting Mill Pulverisette 15, (b) Cutting Rotor and Sieve Inserts and (c) Grinding Chamber

\subsection{Reduction Studies}

Spherical pellets were formed from pulverised iron oxide and polyurethane $(\sim 30 \mathrm{wt} \%)$ with about 2 wt \% flour as binder and appropriate amount of water without flux addition (Fig. 3). After curing and drying for 96 hours the composite pellets were then ready for firing in a resistance heated horizontal tube furnace (Fig. 4).

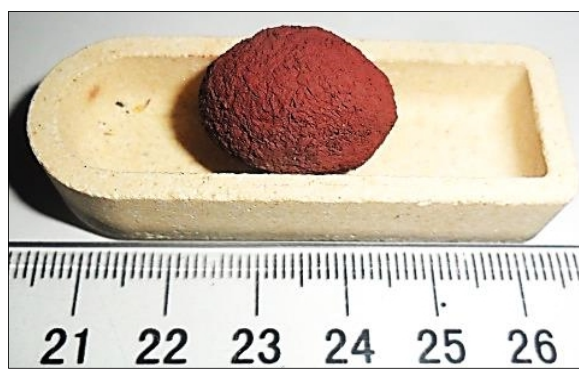

Fig. 3 Spherical Pellet of $\mathrm{Fe}_{2} \mathrm{O}_{3}$-PU Composite

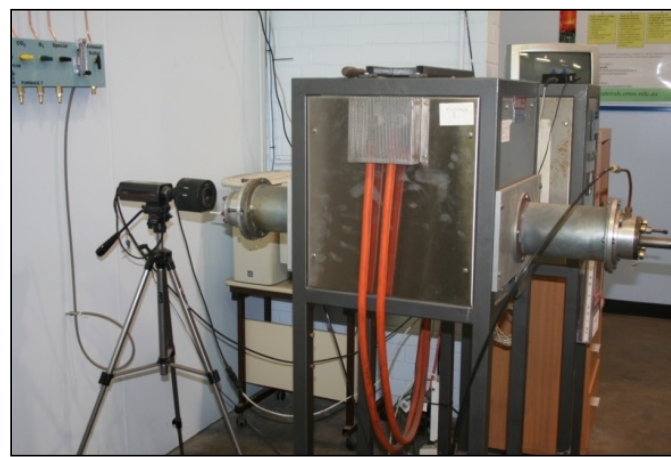

Fig. 4 Horizontal Tube Furnace used for Reduction Studies

The furnace was purged continuously with argon gas (99.995\% purity) to ensure an inert atmosphere. The furnace was preheated to the desired temperature and the sample was inserted; gas measurement commenced immediately after insertion and continued for $1800 \mathrm{~s}$. No appreciable change in gas composition was observed beyond 1800 s. Reacted carbonaceous material/iron oxide samples were quenched by rapidly withdrawing the tray from the hot zone into the cold zone of the furnace. Particles of reduced iron metal, which were clearly visible to the naked eye, were removed by a magnetic screw driver and its oxygen content was determined by LECO Nitrogen/Oxygen analyser (model TC-436 DR 602500-600, LECO Corporation, Michigan, USA) for its $\mathrm{O}$ content.

\section{Results and Discussion}

\subsection{Reduction Studies}

\subsubsection{Gas Generation Behaviour during Heating of $\mathrm{Fe}_{2} \mathrm{O}_{3}$-PU at $1200{ }^{\circ} \mathrm{C}$ and $1500{ }^{\circ} \mathrm{C}$}

The gas generation behaviour in the preheated furnace at $1200{ }^{\circ} \mathrm{C}$ is illustrated in Fig 5. The major component of the offgas is $\mathrm{CO}$ with a maximum concentration of about $7.13 \mathrm{vol} \%$; some $\mathrm{CO}_{2}$ is also observed. 


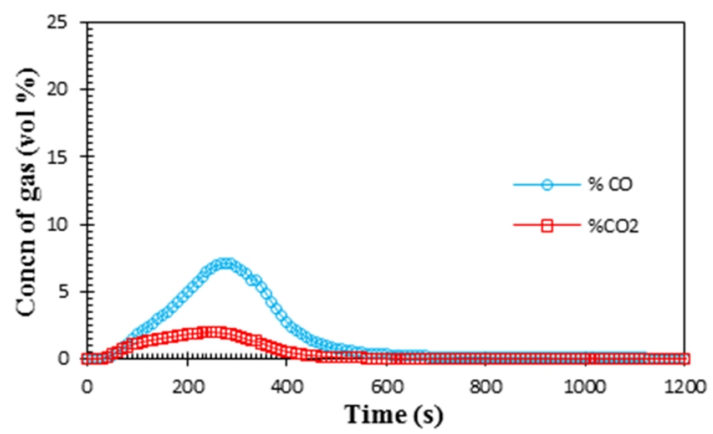

Fig. 5 Gas Generation Behaviour during Heating of $\mathrm{Fe}_{2} \mathrm{O}_{3}$-PU Composite at 1200 ${ }^{\circ} \mathrm{C}$

Temperature appears to have a very significant effect on gas generation, especially $\mathrm{CO}$ as illustrated in Fig. 6. The maximum concentration of $\mathrm{CO}$ increased from about 7.13 vol $\%$ at $1200{ }^{\circ} \mathrm{C}$ to about $23.0 \mathrm{vol} \%$ at $1550{ }^{\circ} \mathrm{C}$, implying that reduction (oxygen removal) is influenced by temperature. The effect of temperature on $\mathrm{CO}_{2}$ is rather the reverse of what was observed for $\mathrm{CO}$, judging from the area under the graphs of $\mathrm{CO}_{2}$ in Figs (5 and 6). This is explained by the consumption of $\mathrm{CO}_{2}$ by solid carbon through the highly endothermic Boudouard reaction (Equation 1), which is favoured at high temperatures (Knacke et al., 1991)

$$
\begin{aligned}
& \mathrm{CO}_{2}+\mathrm{C}=2 \mathrm{CO} \\
& \Delta G=+170700-174.5 T \quad \mathrm{~J}
\end{aligned}
$$

Another possible reaction that could contribute to the observed surge in the concentration of $\mathrm{CO}$ at $1550{ }^{\circ} \mathrm{C}$ is the water gas reaction illustrated in Equation 2 (Knacke et al., 1991):

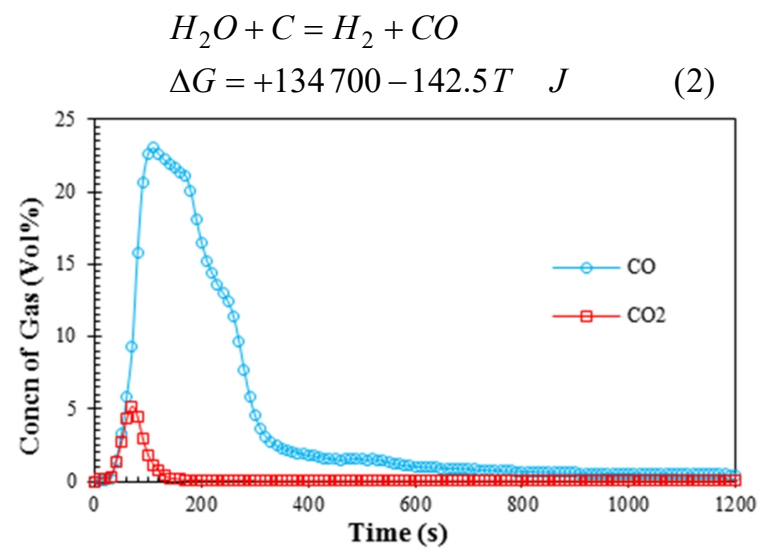

Fig. 6 Gas Generation Behaviour during
Heating of $\mathrm{Fe}_{2} \mathrm{O}_{3}-\mathrm{PU}$ Composite at 1550
${ }^{\circ} \mathrm{C}$

The accumulated amount of gases evolved (nCO and $\mathrm{nCO}_{2}$ ) are shown in Figs 7 and 8 at $1200{ }^{\circ} \mathrm{C}$ and $1550{ }^{\circ} \mathrm{C}$, respectively. This again shows that an increase in temperature leads to an increase in the amount of $\mathrm{CO}$ and a decrease in the amount of $\mathrm{CO}_{2}$ produced.

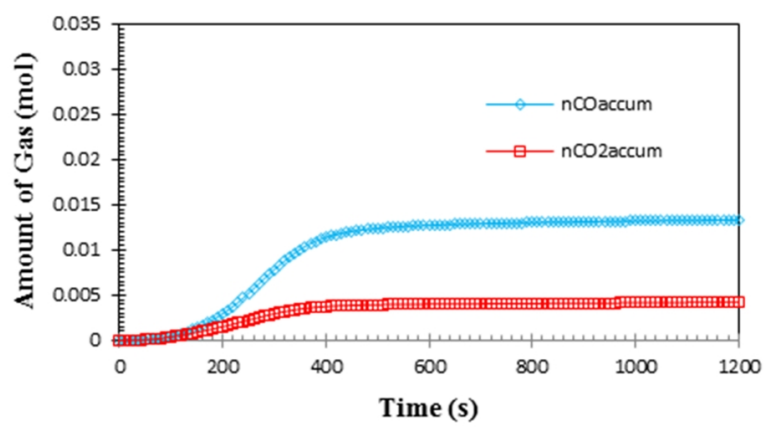

Fig. 7 Accumulated Amount of Gas Generated at $1200{ }^{\circ} \mathrm{C}$

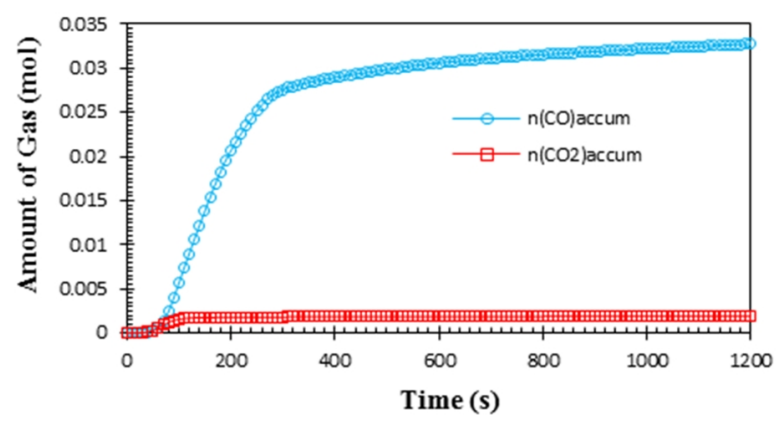

Fig. 8 Accumulated Amount of Gas Generated at $1550{ }^{\circ} \mathrm{C}$

Possible reactions for the reduction of $\mathrm{Fe}_{2} \mathrm{O}_{3}$ to $\mathrm{Fe}$ are:

$$
\begin{aligned}
& \mathrm{Fe}_{2} \mathrm{O}_{3}+3 \mathrm{C}=2 \mathrm{Fe}+3 \mathrm{CO} \\
& \mathrm{Fe}_{2} \mathrm{O}_{3}+3 \mathrm{CO}=2 \mathrm{Fe}+3 \mathrm{CO}_{2} \\
& \mathrm{Fe}_{2} \mathrm{O}_{3}+3 \mathrm{CH}_{4}=2 \mathrm{Fe}+3 \mathrm{CO}+6 \mathrm{H}_{2} \\
& \mathrm{Fe}_{2} \mathrm{O}_{3}+3 \mathrm{H}_{2}=2 \mathrm{Fe}+3 \mathrm{H}_{2} \mathrm{O}
\end{aligned}
$$

The plots of $\ln \left(\mathrm{P}_{\mathrm{CO}} / \mathrm{P}_{\mathrm{CO} 2}\right)$ versus time are shown in in Fig 9 and Fig 10 at $1200{ }^{\circ} \mathrm{C}$ and $1550{ }^{\circ} \mathrm{C}$ respectively. The plots are asymptotic at both temperatures, with the plot at $1200{ }^{\circ} \mathrm{C}$ approaching 1.3 whilst that at $1550{ }^{\circ} \mathrm{C}$ approaches 3.0. This implies that the Boudouard reaction has a significant influence over the reduction process at both temperatures.

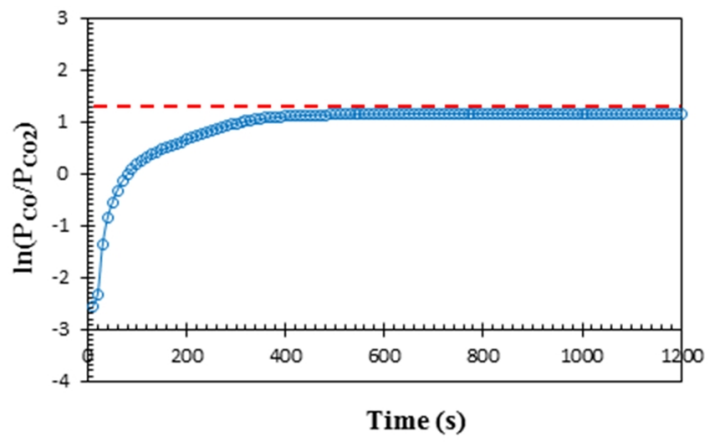

Fig. 9 Variation of $\ln \left(\mathrm{P}_{\mathrm{CO}} / \mathrm{P}_{\mathrm{CO} 2}\right)$ with Time at $1200{ }^{\circ} \mathrm{C}$ 


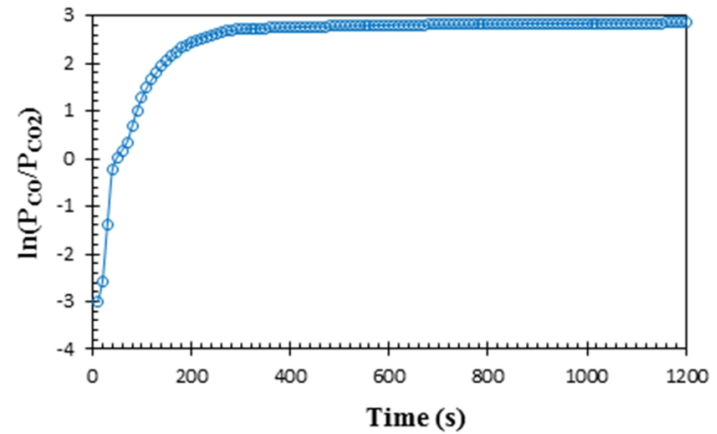

Fig. 10 Variation of $\ln \left(\mathrm{P}_{\mathrm{CO}} / \mathrm{P}_{\mathrm{CO} 2}\right)$ with Time at $1550{ }^{\circ} \mathrm{C}$

\subsubsection{Nature of Metal Produced}

Samples of reduced metal were obtained at all temperatures. However, separation of the metal from the slag depended on the temperature of the furnace. At $1200{ }^{\circ} \mathrm{C}$, metal-slag separation was not attained, as illustrated in Fig. 11.

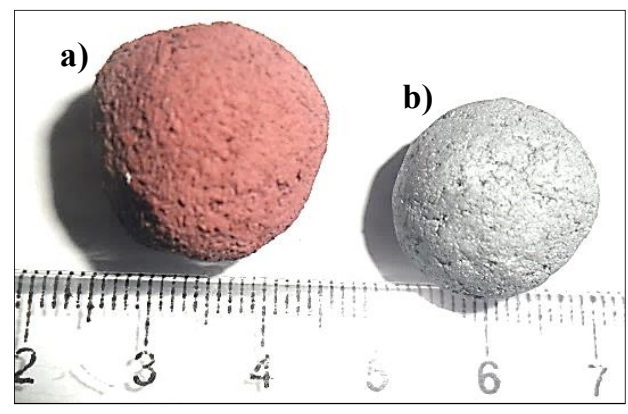

Fig. $11 \mathrm{Fe}_{2} \mathrm{O}_{3}$-PU Composite Pellet a) Before and b) After Reduction at $1200{ }^{\circ} \mathrm{C}$

However, when the temperature was increased to $1550{ }^{\circ} \mathrm{C}$ a clear separation of reduced metal from the slag layer was observed, as shown in Fig. 12. A $\mathrm{LECO} \mathrm{O} / \mathrm{N}$ analyser revealed a reduction in oxygen content from $28.6 \mathrm{wt} \%$ to $0.0532 \mathrm{wt}$, corresponding to about $99.80 \%$ reduction.

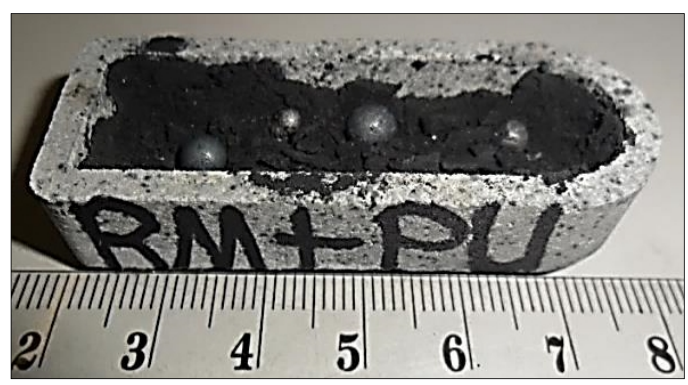

Fig. 12 Droplets of Metallic Iron obtained after Reduction of $\mathrm{Fe}_{2} \mathrm{O}_{3}$-PU Composite at 1550 ${ }^{\circ} \mathrm{C}$

\subsection{Extent of Reduction}

The extent of reduction was calculated from the oxygen content of the reduced metal produced from the reaction of the iron oxide with PU. The results are shown in Figs 13 and 14 for reduction at $1200^{\circ} \mathrm{C}$ and $1550{ }^{\circ} \mathrm{C}$, respectively. At $1200^{\circ} \mathrm{C}$, PU is able to reduce $\mathrm{Fe}_{2} \mathrm{O}_{3}$, attaining an extent of reduction of about 64\%, after $20 \mathrm{~min}$. As the reduction temperature increased from $1200{ }^{\circ} \mathrm{C}$ to $1550{ }^{\circ} \mathrm{C}$, reduction essentially reached completion in less than $4 \mathrm{~min}$.

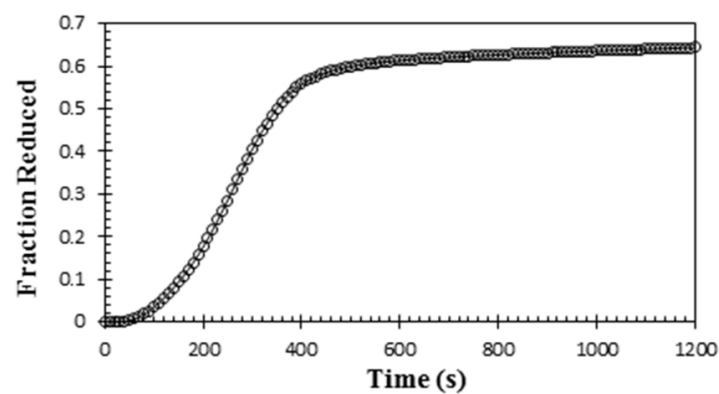

Fig. 13 Variation of Fraction Reduced with Time at $1200{ }^{\circ} \mathrm{C}$

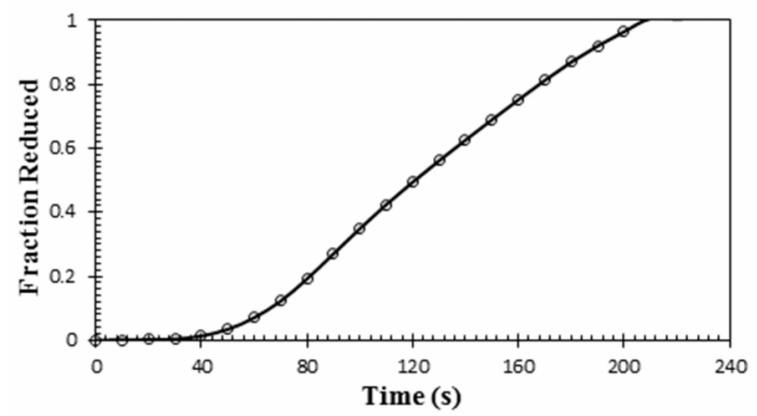

Fig. 14 Variation of Fraction Reduced with Time at $1550{ }^{\circ} \mathrm{C}$

\section{Conclusions}

The reduction of iron oxide $\left(\mathrm{Fe}_{2} \mathrm{O}_{3}\right)$ has been investigated using carbonaceous material prepared from waste PU as reductant. Major findings of the investigation are:

(i) Waste polyurethane foam (PU) is a potential source of carbonaceous materials for iron oxide reduction;

(ii) $\mathrm{CO}$ emissions showed an increase with an increase in temperature;

(iii) At $1200{ }^{\circ} \mathrm{C}$ extent of reduction could only reach about $64 \%$. However, complete reduction of iron oxide was observed in less than $4 \mathrm{~min}$ of reaction when the temperature was increased to $1550{ }^{\circ} \mathrm{C}$.

\section{Acknowledgements}

Part of the analyses for the investigation was conducted at the School of Materials Science and Engineering, UNSW, Sydney, Australia. The authors are grateful to the various authorising bodies for the assistance received. 


\section{References}

Dankwah, J. R., Koshy, P., Saha-Chaudhury, N. M., O'Kane, P., Skidmore, C., Knights, D. and Sahajwalla, V. (2011), "Reduction of $\mathrm{FeO}$ in EAF Steelmaking Slag by Blends of Metallurgical Coke and Waste Plastics", ISIJ International, Vol. 51, No. 3, pp. 498 - 507.

Dankwah, J. R., Koshy, P., O'Kane, P. and Sahajwalla, V. (2012), "Reduction of $\mathrm{FeO}$ in EAF Steelmaking Slag by Blends of Metallurgical Coke and End-of-Life Tyres", Steel Research International, Vol. 83, No.8, pp. $766-774$

Dankwah, J. R., Koshy P. and Sahajwalla, V. H. (2013), "Reduction of FeO in EAF Steelmaking Slag by Blends of Metallurgical Coke and Endof-Life Polyethylene Terephthalate", Ironmaking and Steelmaking, Vol. 41, No. 6, pp. 401- 409.

Dankwah, J.R., and Koshy, P. (2014), "Reduction of $\mathrm{FeO}$ in EAF Steelmaking Slag by Blends of Metallurgical Coke and Waste Polypropylene". High Temperature Materials and Processes, Vol. 33, No. 2, pp. 107 - 114.

Dankwah, J. R. and Baawuah, E. (2015), "Recycling Waste Bakelite as a Carbon Resource in Ironmaking", International Journal of Scientific and Technology Research (IJSTR), Vol. 4, Issue 2, pp. 257 - 261.

Dankwah, J. R., Amoah, T., Dankwah, J. and Fosu, A. Y., (2015), "Recycling Mixed Plastics Waste as Reductant in Ironmaking", Ghana Mining Journal, Vol. 15, No. 2, pp. 73 - 80.

Knacke, O., Kubaschewski, O., and Hasselmann, K. (1991), Thermochemical Properties of Inorganic Substances I, Springer Verlag, 2nd Ed., 129 pp.

Kongkarat, S., Khanna, R., Koshy, P., O’Kane, P., and Sahajwalla, V. (2011), "Use of Waste Bakelite as a Raw Material Resource for Recarburization in Steelmaking Processes" Steel Research International, Vol. 82(10), pp. 1228 - 1239.

Mansuri, I. A., Khanna, R., Rajarao, R. and Sahajwalla, V., (2013), "Recycling Waste CDs as Carbon Resource: Dissolution of Carbon into Molten Iron at $1550{ }^{\circ} \mathrm{C} "$, ISIJ International, Vol. 53, No. 12, pp. 2259 - 2265.

Matsuda, T., Takekawa, M., Hasegawa, M., Ikemura, Y., Wakimoto, K., Ariyama, T., and Iwase, M. (2006), "Utilization of Waste Wood for Production of Iron, Carbon Monoxide and Hydrogen without Generating Carbon Dioxide", Steel Res. Int., Vol. 77, pp. 774 - 784.

Matsuda, T., Hasegawa, M., Ikemura, A., Wakimoto, K., and Iwase, M. (2008), "Utilization of Waste Plastic for Production of Metallic Iron, Hydrogen and Carbon Monoxide without Generating Carbon Dioxide", ISIJ Int., Vol. 48, No. 9, pp. 1186 - 1196.
Murakami, T., Akiyama, T. and Kasai, E., (2009), "Reduction Behaviour of Hematite Composite containing Polyethylene and Graphite with Different Structures with Increasing Temperature", ISIJ Int., 49(6), pp. 809 - 814.

Murakami, T. and Kasai, E., (2011), "Reduction Mechanism of Iron Oxide-carbon Composite with Polyethylene at Lower Temperature", ISIJ Int., 51(1), pp. 9 - 13.

Nath, D. C. D., Mansuri, I. A., Zaharia, M., Saha Chaudhury, N. and Sahajwalla, V., (2012), "Recycling End-of-Life Melamine at $1600{ }^{\circ} \mathrm{C}$ for Carbon Dissolution into Liquid Iron", ISIJ International, Vol. 52, No. 5, pp. 922 - 927.

Nishioka, K., Taniguchi, T., Ueki, Y., Ohno, K., Maeda, T., and Shimizu, M. (2007), "Gasification and Reduction Behaviour of Plastic and Iron Ore Mixtures by Microwave Heating”, ISIJ Int., Vol. 47, No. 4, pp. 602 607.

Rajarao, R., Mansuri, I. A., Dhunna, R., Khanna, R. and Sahajwalla, V., (2014), "Characterisation of Gas Evolution and Char Structural Change during Pyrolysis of Waste CDs", Journal of Analytical and Applied Pyrolysis, Vol. 105, pp. 14 - 22.

Rajarao, R., Mansuri, I., Dhunna, R. and Sahajwalla, V., (2014), "Study of Structural Evolution of Chars during Rapid Pyrolysis of Waste CDs at Different Temperatures", Fuel, Vol. 134, pp. 17 - 25.

Ueki, Y., Ohno, K., Maeda, T., Nishioka, K. and Shimizu, M. (2008), "Reaction Behaviour during Heating Waste Plastic Materials and Iron Oxide Composites", ISIJ Int., Vol. 48, pp. 1670 -1675 .

\section{Authors}

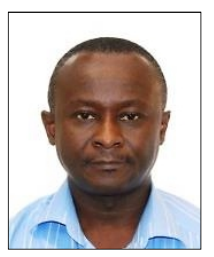

James R. Dankwah obtained his PhD from the School of Materials Science and Engineering, UNSW-Australia, MSc (Process Metallurgy) from the Norwegian University of Science and Technology and BSc (Metallurgical Engineering) from the Kwame Nkrumah University of Science and Technology, Kumasi, Ghana. His current research areas include iron and steelmaking, hightemperature metallurgical processes, utilisation of waste polymers in metal extraction processes and recycling plastic and agricultural waste into building blocks materials for affordable housing for rural folks.

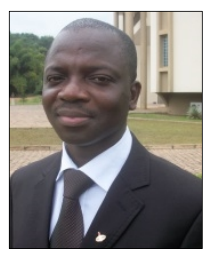

W. K. Buah holds a $\mathrm{PhD}$ in Waste Processing Engineering from the University of Leeds, Leeds, UK and a Master of Science Degree in Mineral Processing Engineering from the Mining Institute of Krivoy Rog, Krivoy Rog, Ukraine. He is currently an Associate Professor at the University of Mines and Technology, Tarkwa, Ghana. His current research interests include mineral processing and extractive metallurgy, waste management, pyrolysis-gasification of wastes and biomass to produce valuable products, including activated carbon for gold adsorption. He is a member of the Society for Mining, Metallurgical and Exploration Engineers (SME) and the Chattered Institute of Waste Management, UK. 